\title{
REALISASI PENGENDALI ON-OFF HISTERISIS DENGAN OPERATIONAL AMPLIFIER (OP-AMP)
}

\author{
DistaYoel Tadeus, Arkhan Subari, Saiful Manan \\ Program Studi Diploma III Teknik Elektro \\ Sekolah Vokasi Universitas Diponegoro \\ e-mail : distayoel@live.undip.ac.id
}

\begin{abstract}
Dista Yoel Tadeus, Arkhan Subari, Saiful Manan, in this paper explain that the realization of the OnOff control system can be built using the comparator principle. The principle has a weakness that is the possibility of chattering due to 'thin' limit of comparator switching. Low immunity to noise increases chances of chattering, if not anticipated it will cause 'fatigue' on actuator thus reducing component's lifetime. Hysteresis has features to suppress chattering. This article describes how to realize the hysteresis On-Off controller using Operational Amplifier (Op-Amp) which is simple and cheap discrete electronics component, by modifying the Op-Amp comparator circuit so that it has the hysteresis band with minimum and maximum limit variable so that the reference point of the comparator can be shifted.
\end{abstract}

Keywords: On-Off Controller, Chattering, Hysterisis, Op-Amp Comparator

\section{PENDAHULUAN}

\section{Latar belakang}

Sistem kendali On-Off merupakan topologi sistem kendali yang paling sederhana dan banyak diterapkan baik dalam proses industri maupun keperluan rumah tangga seperti aplikasi refrigerasi dan pengkondisi udara, pengatur ketinggian air di penampungan, pengatur kipas/blower, pemanas air, dsb. Sistem kendali On-Off memiliki batasanbatasan yang berhubungan dengan implementasi pada sistem yang bervariasi ${ }^{[1,6]}$. Demi mencapai performa sistem yang tinggi, pengendali On-Off dapat dimodifikasi menjadi lebih kompleks seperti ${ }^{[5]}$ dengan menambahkan filter linier dan penguat adaptif pada aplikasi sistem freezer rumah tangga.

$$
\text { Pengendali On-Off optimal }
$$
diimplementasikan di sistem chilled water cooling, di mana temperature chilled water dan energi masukan ke chiller digunakan sebagai fungsi objektif $^{[4]}$. Algoritma dan perhitungan pengendali On-Off yang kompleks membutuhkan mikroprosesor dan pengolah sinyal digital sebagai perangkat realisasinya. Beban komputasi yang besar akan berimbas pada kebutuhan spesifikasi dan biaya yang tinggi.

Aplikasi lain beberapa masih dapat ditangani dengan baik oleh pengendali On-Off konvensional sederhana dengan histerisis seperti pada pengendalian temperature sistem refrigerasi kendaraan transportasi pengangkut barang ${ }^{[2,3]}$. Oleh karena kesederhanaanya, pengendali On-Off konvensional histerisis dapat dibangun menggunakan perangkat Op-Amp yang tentunya jauh lebih murah dibandingkan mikroprosesor.

\section{Analisis Situasi}

Pengendali On-Off adalah pengendali yang sederhana karena tidak melakukan komputasi aritmatika yang kompleks. Prinsipnya hanya dengan membandingkan besaran yang diukur dengan besaran referensi. Keluarannya pun hanya dua keadaan yaitu keadaan On dan Off. Oleh karena itu realisasi pengendali On-Off harus dapat dibangun dari komponen yang juga sederhana dan murah. OpAmp secara alami memiliki fungsi komparator (pembanding) sehingga dapat digunakan untuk merealisasikan pengendali On-Off. Efek chattering adalah fenomena yang sering muncul pada rangkaian komparator akibat 'tipisnya' batas switching, sehingga perlu diterapkan prinsip histerisis di rangkaian komparator pada pengendali On-Off.

\section{Permasalahan}

Yang menjadi permasalahan adalah :

- Diperlukan realisasi pengendali On-Off yang sederhana dan murah

- Pengendali On-Off harus bebas dari efek chattering

- Pengendali On-Off harus memiliki karakter histerisis yang dapat diatur lebar pitanya

\section{Tujuan}

Tujuan penulisan artikel ini adalah:

- Menyediakan salah satu cara realisasi pengendali On-Off yang sederhana dan murah dengan menggunakan Op-Amp

- Menyediakan rancangan pengendali On-Off yang memiliki karakter histerisis dan bebas chattering 


\section{Manfaat}

Manfaat dari penulisan artikel ini antara lain :

- Berbagi ilmu tentang pengendali On-Off

- Berbagi ilmu tentang komparator Op-Amp

- Berbagi ilmu tentang efek chattering dan histerisis

- Berbagi informasi dunia elektro bagi pembaca, diluar bidang ilmu elektro.

\section{KOMPARATOR}

Jantung dari sebuah pengendali On-Off adalah komparator. Dalam aplikasi elektronika, fungsi komparator dengan mudah dibentuk oleh komponen Operational Amplifier (Op-Amp). OpAmp dalam konfigurasi umpan terbuka dapat difungsikan sebagai komparator.

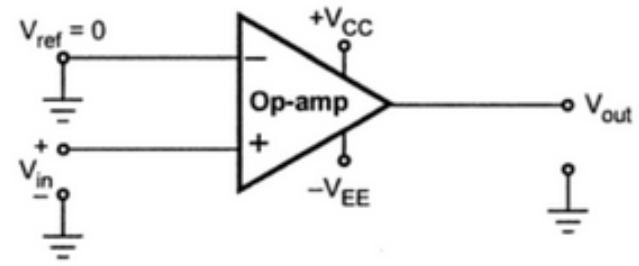

Gambar 1. Komparator non-inverting

Rangkaian komparator Op-Amp membandingkan tegangan sinyal yang masuk di kedua terminal masukannya. Salah satu terminal diberi tegangan konstan sebagai tegangan referensi. Terminal yang lain berfungsi sebagai masukan sinyal luar misalnya dari sensor atau transduser elektronik. Terdapat dua jenis komparator Op-Amp yaitu komparator non-inverting dan komparator inverting. Gambar 1 menunjukkan karakteristik transfer ideal dan praktis komparator non-inverting.

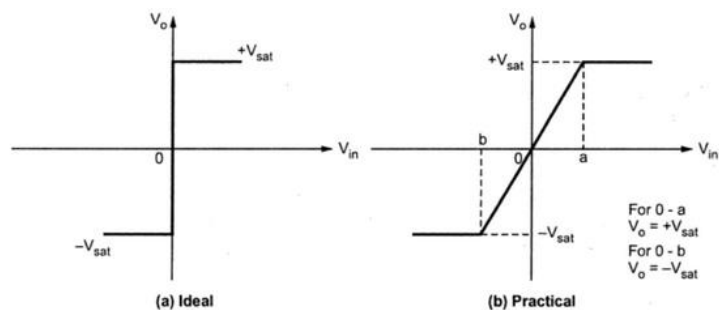

Gambar 2. Karakteristik transfer ideal dan praktis komparator non-inverting

Komparator inverting memiliki prinsip yang sama dengan komparator non-inverting hanya saja terminal masukan dan keluarannya berkebalikan. Gambar 2 menunjukkan karakteristik transfer ideal dan praktikal komparator inverting.

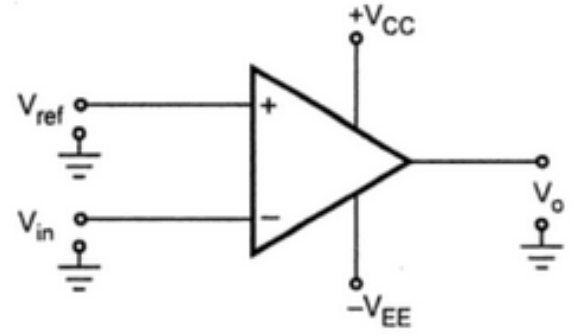

(a)

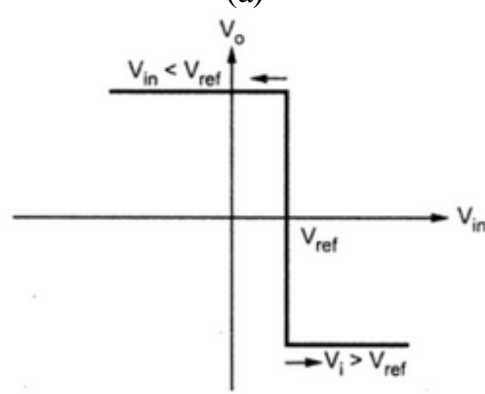

(b)

Gambar 3. Komparator inverting (a) dan karakteristik transfer idealnya dengan $\mathrm{V}_{\text {ref }} \neq 0 \mathrm{~V}$ (b)

\section{Chattering pada komparator}

Pada pengendali On-Off, contohnya dalam aplikasi pengendalian temperatur dengan aktuator berupa elemen pemanas, ketika temperatur berada di bawah nilai referensi maka elemen pemanas akan aktif sampai kemudian temperatur naik melebihi nilai referensi yang menyebabkan elemen pemanas menjadi non-aktif.

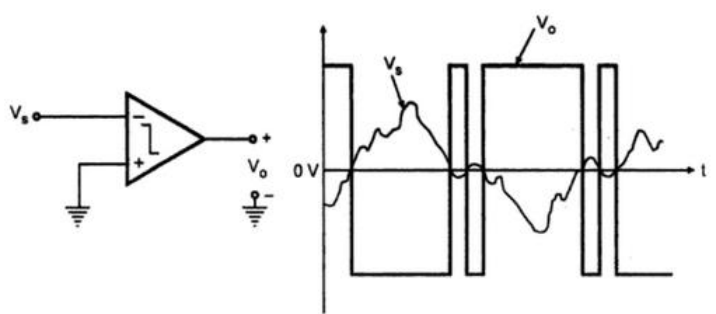

Gambar 4. Fenomena chattering pada komparator

Di dalam praktiknya, sinyal masukan dari sensor/tranduser temperatur akan selalu terkotori oleh derau. Ketika magnituda sinyal masukan berada di sekitar titik referensi, derau akan sangat berpengaruh terhadap keluaran komparator seperti yang ditunjukkan oleh Gambar 4. Derau yang sangat kecil pun dapat menyebabkan chattering oleh karena penguatan umpan terbuka Op-Amp yang sangat besar. Chattering menyebabkan keluaran komparator berfluktuasi sangat cepat sehingga meningkatkan frekuensi aktuasi pada aktuator. Kondisi tersebut tidak diharapkan karena berpotensi merusak aktuator.

\section{EFEK HISTERISIS}

Histerisis secara natural terdapat dalam material magnetik, ferromagnetik, dan ferroelektrik. Sistem yang memiliki histerisis dipandang sebagai 
sistem yang memiliki memori, di mana efek masukan ke sistem akan dapat dirasakan setelah rentang waktu tertentu. Hal tersebut layaknya karakter elastis pada material mekanis ketika diberi atau dibebaskan dari sebuah gaya tertentu.

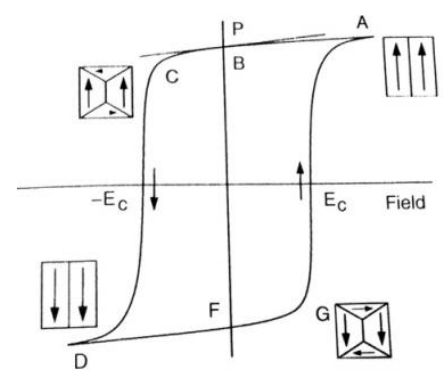

Gambar 5. Histerisis di dalam material ferroelektrik

Gambar 5 menunjukkan salah satu contoh karakteristik transfer material ferroelektrik yang memiliki sifat histerisis.

\section{REALISASI PENGENDALI HISTERISIS DENGAN OP-AMP}

ON-OFF

Efek histerisis dibangun dengan menciptakan dua nilai referensi pada komparator yang dapat berubah sesuai dengan status keluaran komparator yaitu $\mathrm{V}_{\mathrm{TH}}$ yang merupakan referensi batas atas dan $\mathrm{V}_{\mathrm{TL}}$ yang merupakan referensi batas bawah. Ketika sebuah sinyal masukan bertambah sampai melewati $\mathrm{V}_{\mathrm{TH}}$, keluaran komparator akan berubah status dan tetap tidak berubah apabila sinyal masukan berkurang melewati $\mathrm{V}_{\mathrm{TH}}$. Keluaran komparator baru akan berubah status apabila sinyal masukan berkurang terus sampai melewati $\mathrm{V}_{\mathrm{TL}}$ seperti yang ditunjukkan oleh Gambar 6.

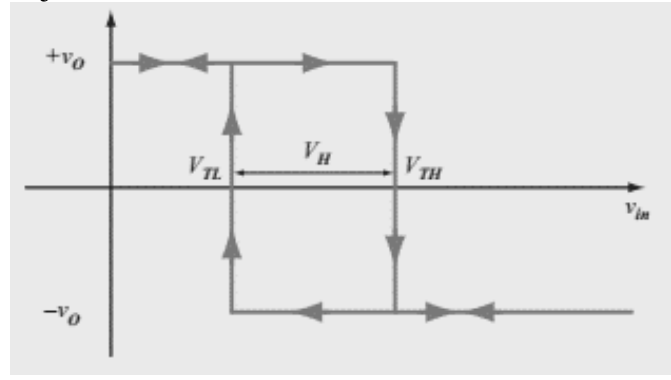

Gambar 6. Kurva histerisis

Komparator memiliki dua status keluaran yang berkorespondensi pada dua tegangan yang berbeda. Dua tegangan yang berbeda inilah yang akan digunakan untuk mengubah atau menggeser tegangan referensi komparator sehingga membentuk $\mathrm{V}_{\mathrm{TH}}$ dan $\mathrm{V}_{\mathrm{TL}}$. Apabila $\mathrm{V}_{\mathrm{TH}}$ terlampaui maka tegangan referensi komparator akan berubah menjadi $\mathrm{V}_{\mathrm{TL}}$, begitu $\mathrm{V}_{\mathrm{TL}}$ terlampaui maka tegangan referensi komparator akan berubah menjadi $\mathrm{V}_{\mathrm{TH}}$.

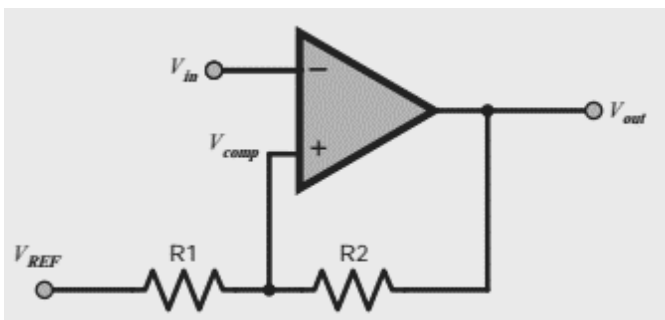

Gambar 7. Komparator dengan umpan balik positif

Mekanisme tersebut dapat direalisasikan dengan menambahkan rangkaian pembagi tegangan pada komparator seperti yang ditunjukkan oleh Gambar 7 membentuk rangkaian komparator dengan umpan balik positif.

Dengan membuat asumsi awal $V_{\text {in }}$ kurang dari $V_{T H}$, $V_{\text {out }}=+V_{o}$. Kondisi ini akan tetap sampai $V_{\text {in }}=$ $V_{\text {comp }}=V_{T H}$. Dengan prinsip pembagi tegangan maka

$V_{T H}=\frac{R_{2}}{R_{1}+R_{2}} V_{\text {ref }}+\frac{R_{1}}{R_{1}+R_{2}} V_{o}$

Apabila $V_{\text {in }}$ meningkat melebihi $V_{T H}, V_{\text {out }}=-V_{o}$. Kondisi ini akan membuat $V_{\text {comp }}=V_{T L}$.

$V_{T L}=\frac{R_{2}}{R_{1}+R_{2}} V_{\text {ref }}-\frac{R_{1}}{R_{1}+R_{2}} V_{o}$

Kondisi $V_{\text {out }}=-V_{o}$ akan tetap sampai $V_{\text {in }}$ berada di bawah $V_{T L}$. Histerisis atau perbedaan antara kedua titik referensi komparator tersebut dinyatakan oleh,

$V_{H}=V_{T H}-V_{T L}=\frac{2 R_{1}}{R_{1}+R_{2}} V_{o}$

Sehingga dengan mengkombinasikan $V_{o}, R_{1}$, dan $R_{2}$ dapat ditentukan lebar pita histerisis pada sebuah komparator.

Berikut ini adalah contoh perhitungannya, apabila $V_{o}= \pm 9 \mathrm{~V}$, tegangan referensi $1 \mathrm{~V}$, dan $R_{1}=1 \mathrm{k} \Omega$. Diinginkan bahwa pengendali On-Off harus memiliki histerisis sebesar $2 \mathrm{~V}$, maka

$V_{H}=\frac{2 R_{1}}{R_{1}+R_{2}} V_{o}$

$2=\frac{2 * 1000}{1000+R_{2}} * 9$

$R_{2}=8 \mathrm{k} \Omega$

Dengan menggunakan persamaan sebelumnya untuk perhitungan $V_{T H}$ dan $V_{T L}$, didapat $V_{T H}=1.889 \mathrm{~V}$ dan $V_{T L}=-0.111 \mathrm{~V}$. Gambar 8 menunjukkan grafik simulasinya, tampak bahwa lebar histerisis yang dimiliki adalah 2V. $V_{R E F}=1 \mathrm{~V}$ menyebabkan pengendali On-Off memiliki karakter histerisis lebih lebar ke $V_{T L}$ daripada $V_{T H}$ atau dengan kata lain tidak simetris terhadap tegangan referensi.

Gambar 9 menunjukkan grafik hasil simulasi dengan nilai parameter yang sama tetapi menggunakan $V_{R E F}=5 \mathrm{~V}$. Tampak bahwa karakter histerisis jauh semakin melebar ke $V_{T L}$ daripada $V_{T H}$ terhadap $V_{R E F}$. Hal tersebut disebabkan oleh $V_{R E F}$ yang tidak berada di tengah-tengah antara dua tegangan switching OpAmp (antara $V_{o}$ dan $\left.-V_{o}\right)$. Pada contoh perhitungan sebelumnya, apabila $V_{R E F}=0 \mathrm{~V}$ akan membuat karakteristik histerisis menjadi simetris terhadap $V_{R E F}$. 


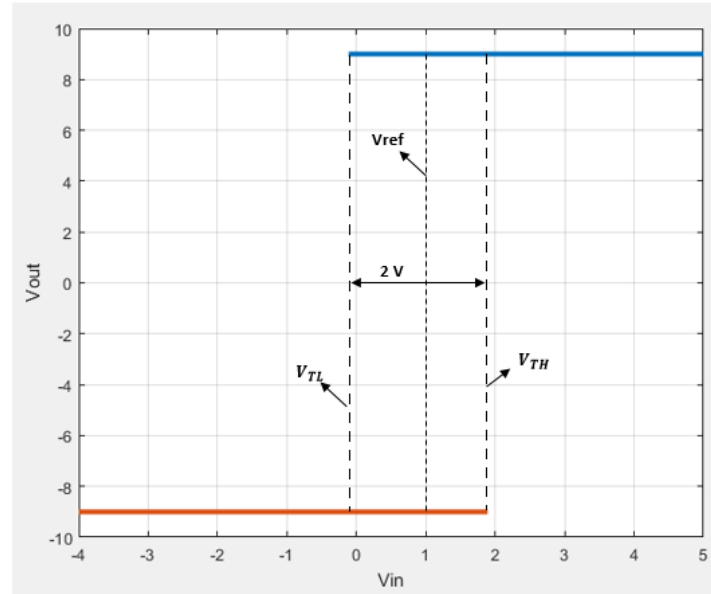

Gambar 8.Grafik simulasi $V_{R E F}=1 \mathrm{~V}$

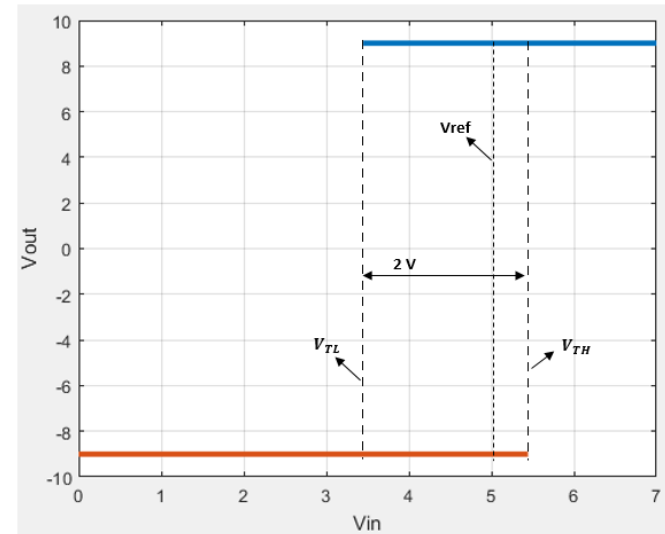

Gambar 9.Grafik simulasi $V_{R E F}=5 \mathrm{~V}$

Perlu diketahui bahwa persamaan (1)-(3) berlaku hanya untuk Op-Amp yang menggunakan catu daya simetris $\quad\left(V_{\text {out }}= \pm V_{o}\right)$. Apabila Op-Amp menggunakan catu daya tunggal $\left(0 \mathrm{~V}\right.$ dan $\left.V_{C C}\right)$ maka rangkaian komparator perlu dimodifikasi menjadi seperti Gambar 10.

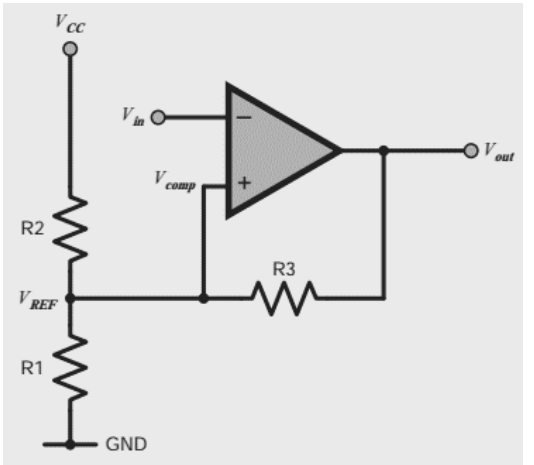

Gambar 10. Komparator umpan balik positif dengan pembagi tegangan

Gambar 10 menunjukkan rangkaian komparator umpan balik positif yang disertai rangkaian pembagi tegangan $R_{1}$ dan $R_{2}$. Tampak bahwa tegangan referensi komparator dipengaruhi oleh rangkaian pembagi tegangan, sehingga

$V_{T H}=\frac{R_{1}}{R_{1}+R_{P 23}} V_{C C}$ dan

$V_{T L}=\frac{R_{P 13}}{R_{P 13}+R_{P 2}} V_{C C}$

di mana $R_{P 23}$ adalah nilai hambatan parallel $R_{2}$ dan $R_{3}$, sedangkan $R_{P 13}$ adalah nilai hambatan parale $1 R_{1}$ dan $R_{3}$

\section{KESIMPULAN}

- Pengendali On-Off histerisis dapat direalisasikan dengan baik menggunakan komponen elektronika yang murah dan sederhana yaitu OpAmp dan resistor.

- Rangkaian komparator adalah prinsip utama dalam membangun pengendali On-Off.

- Histerisis diterapkan dalam rangkaian komparator untuk menghilangkan efek chattering.

- Lebar pita histerisis dapat ditentukan dengan mengatur nilai $R_{1}, R_{2}, V_{R E F}$, dan $V_{o}$ pada Op-Amp yang menggunakan catu daya simetris.

- Lebar pita histerisis dapat ditentukan dengan mengatur nilai $R_{1}, R_{2}, R_{3}$, dan $V_{C C}$ pada Op-Amp yang menggunakan catu daya tunggal.

- Pada Op-Amp dengan catu daya simetris, $V_{R E F}$ yang tidak berada di sekitar titik tengah tegangan switching Op-Amp akan menyebabkan karakter histerisis menjadi tidak simetris terhada $V_{R E F}$.

\section{DAFTAR PUSTAKA}

1. Deng, H., Larsen, L. F. S., Stoustrup, J., \& Rasmussen, H. (2009). A novel method for control of systems with costs related to switching: applications to air-condition systems. Proceedings of the European Control Conference 2009, 554-559. Retrieved from http://www.control.aau.dk/ jakob/selPubl/papers 2009/ecc_2009_1.pdf, Everyday Practical Electronics. June 2015.

2. James, S. J., Evans, J., \& James, C. (2008). A review of the performance of domestic refrigerators. Journal of Food Engineering, 87(1), 2-10. https://doi.org/10.1016/j.jfoodeng.2007.03.032

3. J. Frith, Temperature prediction software for refrigerated container cargoes, in: Proceedings of the Institute of Refrigeration,2003-2004, pp. 1-12.

4. Jian, W.-L., \& Zaheeruddin, M. (1998). Suboptimal on-off switching control strategies for chilled water cooling systems with storage. Applied Thermal Engineering, 18(6), 369-386. https://doi.org/http://dx.doi.org/10.1016/S13594311(97)00056-2

5. Leva, A., Piroddi, L., \& Boer, A. (2008). Adaptive temperature control in a freezer with on-off actuation. In IFAC Proceedings Volumes (IFAC-PapersOnline) (Vol. 17). https://doi.org/10.3182/20080706-5-KR-

1001.1316 
6. Leva, A., Piroddi, L., Di Felice, M., Boer, A., \& Paganini, R. (2010). Adaptive relay-based control of household freezers with on-off actuators. Control Engineering Practice, 18(1), 94-102.

https://doi.org/10.1016/j.conengprac.2009.09.008 